\title{
Test accuracy of metabolic indicators in predicting decreased fertility in dairy cows
}

\author{
H. Lomander, ${ }^{\star 1}$ H. Gustafsson,† C. Svensson,‡ K. L. Ingvartsen,§ and J. Frössling \# \\ ${ }^{*}$ Department of Animal Environment and Health, Swedish University of Agricultural Sciences, PO Box 234, SE-53223 Skara, Sweden \\ †Swedish Dairy Association and Division of Reproduction, Department of Clinical Sciences, Swedish University of Agricultural Sciences, \\ PO Box 7054, SE-75007 Uppsala, Sweden \\ ¥Växa Sverige, Regional Livestock Association, PO Box 814, SE-39128 Kalmar, Sweden \\ §Department of Animal Sciences, Aarhus University, PO Box 50, DK-8830 Tjele, Denmark \\ \#Department of Disease Control and Epidemiology, National Veterinary Institute, SE-75189 Uppsala, Sweden
}

\begin{abstract}
Negative energy balance is a known risk factor for decreased fertility in dairy cows. This study evaluated the accuracy of plasma concentrations of nonesterified fatty acids (NEFA), $\beta$-hydroxybutyrate (BHBA), and insulin-like growth factor 1 (IGF-1) - factors related to negative energy balance - in predicting decreased fertility. One plasma sample per cow was collected from 480 cows in 12 herds during the period from d 4 to 21 in milk and analyzed for NEFA, BHBA, and IGF1. For each cow, data on breed, parity, calving date, gynecological examinations, and insemination dates were obtained. Milk samples from 241 cows in 7 of the participating herds were analyzed for progesterone concentration to define the first day of luteal activity. The diagnostic sensitivity (Se) and specificity (Sp) at different cut-off concentrations of NEFA, BHBA, or IGF-1 were calculated and related to individual cow fertility status, measured as anestrus (ANEST), delayed first artificial insemination (DFAI), or delayed conception. Positive and negative predictive values $(\mathrm{PV}+$; PV-) were calculated considering different levels of (withinherd) prevalence. Strata (i.e., subgroup)-specific Se and Sp and associations between test results and fertility parameters were investigated using logistic regression. The NEFA and BHBA tests for ANEST and DFAI had the highest combined Se and Sp and were thus evaluated further. Cut-off values with $\mathrm{Sp}$ around $80 \%$ were used in this step to provide a reasonable number of test-positive cows, representing a practical situation. This corresponded to a cut-off value for the NEFA test of $400 \mu \mathrm{Eq} / \mathrm{L}$ (Se 0.27-0.45) and for the BHBA test of $1.8 \mathrm{mM}$ (Se 0.15-0.30) across all cows included in the study. The estimated Sp was generally higher than the original $80 \%$, but the corresponding Se was further
\end{abstract}

Received March 13, 2012.

Accepted August 17, 2012.

${ }^{1}$ Corresponding author: Hanna.Lomander@slu.se decreased when the test was used in heifers compared with older cows. The true prevalence of ANEST in the study population was $27 \%$, which gave a PV+ of 0.36 to 0.45 and a PV- of 0.76 to 0.79 . With $35 \%$ true prevalence of DFAI, PV+ was 0.29 to 0.38 and $\mathrm{PV}-$ was 0.64 to 0.66 . Thus, overall test performance was low when metabolic indicators measured as single values in early lactation were used to predict fertility in dairy cows, but accuracy was influenced by cow-level factors such as parity. The prevalence of the target condition (in this case, decreased fertility) also influences test usefulness and should be considered when planning test systems and interpreting test results.

Key words: sensitivity, specificity, two-graph receiver operator characteristic, negative energy balance

\section{INTRODUCTION}

Decreased fertility causes economic losses (Inchaisri et al., 2010) and has become a major concern in the dairy industry worldwide (Rodriguez-Martinez et al., 2008). In Sweden, fertility traits such as calving interval and the interval between calving and first insemination have increased during the past $20 \mathrm{yr}$, and decreased fertility is today the most common reason for culling cows (Swedish Dairy Association, 2009-2012). To optimize fertility in a herd, methods to identify cows at risk of impaired fertility are greatly needed. A strong association exists between negative energy balance (NEB), a physiological adaptation commonly seen in newly calved cows, and decreased fertility (Friggens, 2003; Ingvartsen, 2006). Therefore, the concentrations of circulating metabolites and hormones involved in energy metabolism after calving could be useful in predicting decreased fertility during the subsequent weeks of lactation. Several studies have shown that plasma concentrations of these metabolites and hormones in late gestation or early lactation are associated with the occurrence of impaired fertility (Patton et al., 2007; Wathes et al., 2007; Ospina et al., 2010b). However, the 
predictive value of metabolites and hormones for the assessment of subsequent reproductive function has not been addressed previously in a large-scale study.

In general, the newly calved cow has decreased DMI, a deficit in glucose precursors, and increased lipolysis, as indicated by low plasma concentrations of glucose, insulin, and IGF-1, together with high plasma concentrations of NEFA and BHBA (Ingvartsen and Andersen, 2000). In contrast to glucose and insulin, which are under homeostatic regulation, plasma concentrations of NEFA and BHBA are under homeorhetic regulation during the transition period and could therefore be useful predictors of energy status (Ingvartsen, 2006). In addition, the peptide hormone IGF-1 is considered indicative of metabolic competency for reestablishment of reproductive function during the postpartum period (Velazquez et al., 2008) and might be useful in this context.

For diagnostic methods that give test results on a continuous scale, the diagnostic sensitivity (Se; the proportion of diseased individuals that test positive) and specificity ( $\mathbf{S p}$; the proportion of healthy individuals that test negative) vary with different cut-off values for the test system. The ideal cut-off value depends on the purpose of the test. For example, if the test will be used to rule out disease, a cut-off value with relatively high Se (and thereby few false negative test results) is needed. If, on the other hand, the test will be used to confirm disease, a cut-off value with a high Sp is preferable. In addition, the prevalence of the event of interest (e.g., decreased fertility) in the population will have a strong influence on the predictive value of the test; that is, the probability that an individual testing positive or negative is actually diseased or nondiseased (Dohoo et al., 2009). It is essential to consider these aspects in the interpretation of test results.

In recent studies, the Se and Sp of measuring serum concentrations of metabolites for the prediction of clinical disease have been evaluated. In a study by Chapinal et al. (2011), the odds of displaced abomasum were 4.3 in cows with NEFA $\geq 1.0 \mathrm{mEq} / \mathrm{L} 1$ wk postpartum. The estimated Se and Sp at this cut-off were 0.51 and 0.80 , respectively. With a lower cut-off (NEFA $\geq 0.57$ $\mathrm{mEq} / \mathrm{L}$ ) and Se and Sp of 0.75 and 0.61, respectively, Ospina et al. (2010b) showed that test-positive cows were 1.9 times more likely to have any one of the diseases displaced abomasum, clinical ketosis, or metritis. In another study, Ospina et al. (2010a) found that, controlling for other risk factors, cows with a postpartum NEFA value $\geq 0.72 \mathrm{mEq} / \mathrm{L}$ had a $16 \%$ decreased probability of conception within $70 \mathrm{~d}$ after the voluntary waiting period. Similarly, cows with BHBA $\geq 100$ $\mathrm{mg} / \mathrm{L}$ were $13 \%$ less likely to become pregnant within
$70 \mathrm{~d}$ after the voluntary waiting period. However, the diagnostic properties of the tests at these cut-off values were not evaluated.

The aim of the present study was to estimate the diagnostic properties of varying plasma concentrations of BHBA, NEFA, and IGF-1 measured in a single sample in early lactation for detecting subsequent impairment of reproductive function. A secondary aim was to estimate strata (i.e., subgroup)-specific Se and Sp for each test, considering cow-level factors that may influence the test results. A final aim was to calculate the predictive values of the tests when applied to populations with different prevalence of decreased fertility.

\section{MATERIALS AND METHODS}

\section{Overview}

Concentrations of NEFA, BHBA, and IGF-1 were measured in plasma from dairy cows during early lactation and related to the reproductive performance of the individual cows. Three different tests to predict impaired fertility based on NEFA, BHBA, and IGF-1 measurements were developed and compared against 3 reference standards for decreased fertility. These reference standards were defined to identify cows experiencing anestrus (lack of ovarian cyclicity; ANEST), delayed first AI after calving (DFAI), and delayed conception (DCON). The diagnostic Se and Sp were calculated at different cut-off values in each test (i.e., measures of NEFA, BHBA, and IGF-1) and compiled in 2-graph receiver operator curves. Strata-specific Se and Sp and associations between test results and fertility parameters at different cut-off values were further investigated using logistic regression. Finally, positive and negative predictive values were calculated considering different levels of (within-herd) prevalence. Editing of data and statistical analyses were performed in Stata (release 11, StataCorp LLP, College Station, TX).

\section{Animals and Herds}

The study was conducted in 12 conventional dairy herds in southwest Sweden and included data from 480 cows collected from October 1, 2007, to February 28, 2009. The herds participating in the study were also enrolled in a study of supplemental feeding with glycerol or propylene glycol in early lactation (Lomander et al., 2012a,b). The use of the animals as research objects was approved by the regional animal ethics committee in Gothenburg, Sweden.

The herds had, on average, 60 cows (range 45-105) and consisted of at least two of the breed categories 
Table 1. Number of samples (\% in parentheses) across breed, parity, and fertility status in a study where the critical thresholds of plasma concentrations of NEFA, BHBA, and IGF-1 were evaluated and used to predict anestrus (ANEST; $\mathrm{n}=241)$, delayed first AI $(\mathrm{DFAI} ; \mathrm{n}=480)$, or delayed conception (DCON; $\mathrm{n}=407)$ in Swedish dairy cows

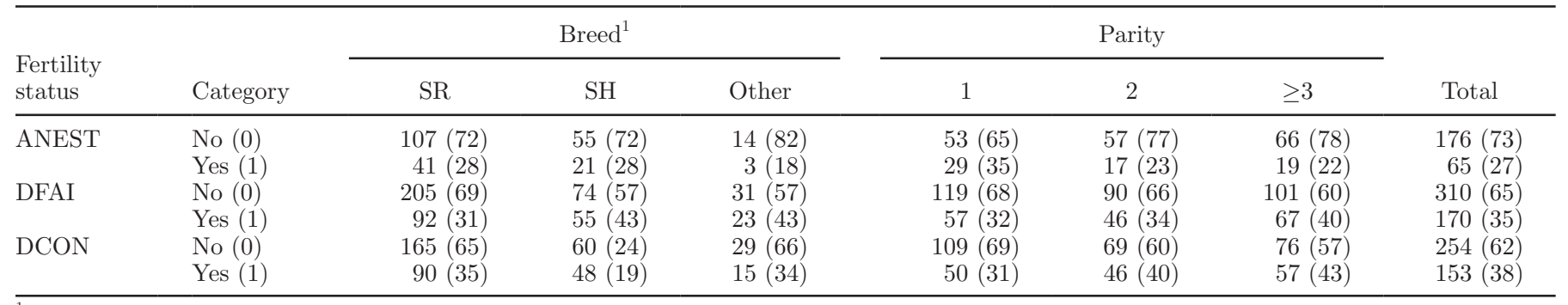

${ }^{1} \mathrm{SR}=$ Swedish Red; $\mathrm{SH}=$ Swedish Holstein; Other $=$ other breed or crossbreed.

Swedish Red (SR), Swedish Holstein (SH), or mixed breed (other; see Table 1). Herds were milked twice daily and produced between 9,100 and $11,500 \mathrm{~kg}$ of ECM per $365 \mathrm{~d}$ and cow. Cows were fed individual diets of grass silage and concentrates according to monthly milk yield and BCS (Spörndly, 2003). All farms had tiestalls but cows were kept on pasture for at least $6 \mathrm{~h} / \mathrm{d}$ for 3 months during summer. In all herds, cows were inseminated following heat detection. Heat detection was carried out by the manager or a trained employee on at least 2 specific occasions when the cows were resting and with no other concurrent activity in the barn. If signs of estrus were registered at other times, these were reported to the stock manager. Further details on management and feeding of the cows are given in Lomander et al. (2012a,b).

All herds included in the study were enrolled in the Swedish official milk recording system (SOMRS), from where data were taken on identities of cows and fertility data. For each individual cow, the data available included the unique identity of the cow, breed, parity, monthly test-day milk yield and composition, calving date, date of inseminations, dates and results of examinations of reproductive function and gynecological treatments, as well as treatments for other diseases.

\section{Collection and Analyses of Samples}

From each cow, a single blood sample was taken in the coccygeal vein or artery between 4 and 21 DIM using a sodium heparin-coated vacuum tube (BD Vacutainer, Becton Dickinson, Plymouth, UK). The samples were immediately placed on ice and were centrifuged at $2,000 \times g$ for 20 min within $1 \mathrm{~h}$ after sampling. Samples of plasma were then stored at $18^{\circ} \mathrm{C}$ until analysis.

For a subset of 241 cows in 7 of the study herds, milk samples were collected twice weekly, starting at 14 DIM and ending when first heat was detected. These milk samples were taken by the farmer immediately after the morning milking and stored at $-18^{\circ} \mathrm{C}$ until analysis for progesterone.

Plasma samples were analyzed for concentrations of NEFA and BHBA using an autoanalyzer (ADVIA 1650 Chemistry System, Siemens Medical Solutions, Tarrytown, NY). Plasma concentrations of IGF-1 were determined using a noncompetitive, time-resolved, immunofluorometric assay as described by Løvendahl and Purup (2002). Milk samples were analyzed for progesterone concentration according to Friggens et al. (2008). All analyses were conducted in the laboratory at AU-Foulum, Aarhus University (Denmark) and are further described in Lomander et al. (2012a,b).

\section{Definitions of Fertility Parameters and Reference Standards}

Three reference standards of decreased fertility (ANEST, DFAI, and DCON) were defined based on DIM at first luteal activity (FLA), first insemination (FAI), and conception (CON), respectively. First luteal activity was defined as the first day postcalving when plasma concentration of progesterone exceeded $4 \mathrm{ng} / \mathrm{mL}$ (Friggens et al., 2008). The day of FAI was defined as the first time after calving when an AI was recorded in SOMRS, and CON was defined as the day after calving of an AI that was followed by a recorded calving within 270 to $290 \mathrm{~d}$, or that was followed by a rectal palpation or ultrasound examination that confirmed pregnancy. Cows treated for ovarian cysts or that received any other type of hormone treatment before the event of interest were not included in statistical analyses $(\mathrm{n}=26)$.

Cows that did not experience FLA, FAI, or CON within the corresponding 75th percentile of DIM for the study population were categorized as having decreased fertility (Table 1). The 75th percentiles for ANEST, DFAI, and DCON were 36, 96, and 145 DIM, respectively. The numbers of samples across breed, parities, and reference standards are shown in Table 1. 


\section{Investigation of Different Cut-Off Values}

The cut-off values tested for each of the 3 test indicators corresponded to different concentrations: at each $50 \mu \mathrm{Eq} / \mathrm{L}$ step for NEFA, at each $0.2 \mathrm{~m} M$ step for BHBA, and at each $10 \mathrm{ng} / \mathrm{mL}$ step for IGF-1. The Se and $\mathrm{Sp}$ at each of the cut-off values of the 3 test indicators were then calculated by the standard crosstabulation technique (Dohoo et al., 2009). In the cross table, cows were distributed across the 3 fertility reference standards (e.g., positive or negative for ANEST, DFAI, or DCON at 36, 96, or 145 DIM, respectively) as well as across whether the test indicators (NEFA, BHBA, or IGF-1) were positive or negative relative to the different cut-off values. In this testing system, a positive test result indicated abnormal reproductive function. Two-graph receiver operating characteristic curves (TG-ROC; Greiner et al., 1995) were then constructed, using the roctg command in Stata, for each indicator and reference standard. In a TG-ROC, the test $\mathrm{Se}$ and $\mathrm{Sp}$ are plotted on the $\mathrm{y}$-axis against all possible cut-off values on the $\mathrm{x}$-axis to visualize how test performance changes with changing cut-off values.

\section{Logistic Regression of Se and Sp}

In the study population, the cut-off values with the highest combined Se and Sp would have classified about $50 \%$ of the cows as test-positive. From a practical perspective, this is not useful so cut-off values of NEFA, BHBA, and IFG-1 with higher Sp were chosen. To give a reasonable number of cows at risk for the calculations, cut-off values with Sp around $80 \%$ were further evaluated. In this step, the IGF-1 results were omitted because of the poor accuracy of the test (based on TG-ROC curves). Furthermore, the fertility measure DCON was omitted from model building and from further evaluation because the multifactorial etiology of decreased conception rates. Thus, NEFA and BHBA tests for ANEST and DFAI were further evaluated.

Estimations of Se and Sp for the chosen tests and cut-off values were made using a logistic model according to Coughlin et al. (1992). In this type of model, the result of the test investigated is the dependent variable. A cow was considered to test positive $(\mathrm{Y}=1)$ if she had a plasma concentration of NEFA or BHBA equal to or greater than the chosen cut-off, and otherwise to test negative $(Y=0)$. The reference standard (i.e., ANEST or DFAI) was included as a dichotomous (0, 1) explanatory variable together with other covariates of interest. The covariates included in the models were breed (SR, SH, or other) and parity $(1,2$, or $\geq 3)$. The clustering effect of farm was included as a random ef- fect. The model was run using the xtlogit command in Stata, treating herd as the panel variable. The general model was

$$
\begin{aligned}
\text { Logit } \operatorname{Pr}(\mathrm{Y}= & \left.1 \mid \mathrm{X}_{1}, \ldots, \mathrm{X}_{\mathrm{k}}\right)=\alpha+\Sigma \beta_{\mathrm{k}} \mathrm{X}_{\mathrm{k}} \\
& +\mu_{\mathrm{m}} \mathrm{Z}_{\mathrm{m}}+\varepsilon_{\mathrm{km}},
\end{aligned}
$$

where $\mathrm{Y}$ is the dichotomous test result at the chosen cut-off value, $\mathrm{X}_{\mathrm{k}}$ denotes the explanatory variables, $\alpha$ is the intercept, $\beta_{\mathrm{k}}$ denotes the regression coefficients for fixed effects, $\mu_{\mathrm{m}}$ is the regression coefficient for $Z_{\mathrm{m}}$, $\mathrm{Z}_{\mathrm{m}}$ is the random effect at the herd level, and $\varepsilon_{\mathrm{km}}$ is the remaining unexplained variation.

When a cow had decreased fertility according to one of the reference standards $\left(\mathrm{X}_{1}=1\right)$, the log odds (logit) of a test result above the chosen cut-off level $(\mathrm{Y}=1)$ were modeled and adjusted for the covariates, and this probability corresponded to the diagnostic Se of the test. In the opposite scenario $\left(\mathrm{X}_{1}=0\right)$, the model can be used to estimate the probability of a cow having a result under the cut-off level $(Y=0)$, which equals $1-$ Sp.

One model for each test and reference standard was built using manual stepwise backward elimination. All variables with Wald $P<0.05$ were kept in the models, plus the reference standard, which was kept regardless of significance. The predicted probabilities (Se and 1 - Sp) and 95\% confidence intervals were obtained by computing the adjusted linear predictions and then transforming these to probabilities. In model evaluation, robust standard errors were applied (Dohoo et al., 2009). The overall fit of the models was assessed by using the Hosmer-Lemeshow test, with the data divided into 10 groups based on deciles of the predicted probabilities. Covariate patterns with large influence on the models were detected through examining plots of leverage against delta- $\beta$ values as described by Hosmer and Lemeshow (2000).

\section{Investigation of Predicted Values at Different Herd-Level Prevalences}

The positive predictive values $(\mathbf{P V}+)$ and negative predictive values $(\mathbf{P V}-)$ were calculated for each test (i.e., the chosen cut-off values of NEFA and BHBA with Sp of approximately $80 \%$ ) at different prevalences of decreased fertility using the same cross-tabulation technique as described earlier. The prevalence used in this step corresponded to the true herd prevalence of ANEST (27\%) and DFAI (35\%), but we also evaluated a hypothetical scenario with high (50\%) and low (15\%) prevalence of ANEST and DFAI. 
Table 2. Median concentrations and interquartile range (Q1; Q3) of NEFA, BHBA, and IGF-1 measured in plasma during d 0 to 21 in milk versus the fertility status of the cow

\begin{tabular}{|c|c|c|c|c|c|c|c|}
\hline \multirow{2}{*}{$\begin{array}{l}\text { Fertility } \\
\text { status }^{1}\end{array}$} & \multirow[b]{2}{*}{ Category } & \multicolumn{2}{|c|}{ NEFA $(\mu \mathrm{Eq} / \mathrm{L})$} & \multicolumn{2}{|c|}{ BHBA $(\mathrm{m} M)$} & \multicolumn{2}{|c|}{ IGF-1 (ng/mL) } \\
\hline & & Median & Q1; Q3 & Median & Q1; Q3 & Median & Q1; Q3 \\
\hline ANEST & No $(0)$ & 247 & $159 ; 377$ & 1.1 & $0.7 ; 1.6$ & 101 & $71 ; 135$ \\
\hline \multirow[t]{2}{*}{ DFAI } & Yes (1) & 312 & $183 ; 729$ & 1.0 & $0.8 ; 1.3$ & 90 & $58 ; 117$ \\
\hline & No $(0)$ & 248 & $165 ; 380$ & 1.1 & $0.7 ; 1.6$ & 100 & $73 ; 138$ \\
\hline $\mathrm{CON}$ & Yes (1) & 277 & $155 ; 377$ & 1.0 & $0.8 ; 1.4$ & 94 & $72 ; 132$ \\
\hline
\end{tabular}

${ }^{1}$ ANEST $=$ anestrus; that is, whether a cow had a first luteal activity at 36 DIM or not $(\mathrm{n}=241)$; DFAI $=$ delayed first AI; that is, whether the cow had a first AI at 96 DIM or not $(\mathrm{n}=480)$; CON = conception; that is, whether the cow had conceived or not at 145 DIM $(\mathrm{n}=407)$.

\section{RESULTS}

Plasma concentrations of NEFA, BHBA, and IGF-1 measured from 4 to 21 DIM showed a skewed distribution and are therefore presented as median values (interquartile range in parentheses). Across all cows, the median plasma concentration of NEFA from 4 to 21 DIM was $278(174-405) \mu \mathrm{Eq} / \mathrm{L}$. The median concentrations of BHBA and IGF-1 were $1.0(0.75-1.51) \mathrm{m} M$ and 97 (67-132) ng/mL, respectively. The distribution of median plasma concentrations of NEFA, BHBA, and IGF-1 across the fertility status of the cows is shown in Table 2.

The cut-off values with the highest combined Se and Sp for each of the 3 tests when used to predict ANEST, DFAI, or CON are shown in Table 3. The NEFA and BHBA tests for ANEST and DFAI fulfilled the selection criteria and were thus further evaluated; results are shown graphically as TG-ROC curves in Figures 1 and 2. The cut-off value for NEFA corresponding to an Sp of approximately $80 \%$ was $400 \mu \mathrm{Eq} / \mathrm{L}$, with Se $=0.45(95 \%$ CI: $0.32-0.57)$ and $\mathrm{Sp}=0.79$ (95\% CI: $0.72-0.85)$ when predicting ANEST, and $\mathrm{Se}=0.27$ (95\% CI: 0.21-0.34) and Sp = 0.76 (95\% CI: 0.71-0.81) when predicting DFAI. However, the corresponding BHBA cut-off value was $1.8 \mathrm{mM}$ with $\mathrm{Se}=0.30(95 \%$
CI: $0.18-0.42)$ and $\mathrm{Sp}=0.80$ (95\% CI: $0.73-0.86)$ when used to predict ANEST and Se $=0.15$ (95\% CI: $0.10-0.22)$ and $\mathrm{Sp}=0.80$ (95\% CI: $0.75-0.84)$ when used to predict DFAI. Of 480 cows, $86(18 \%)$ had a plasma concentration above the selected BHBA cut-off value, $120(25 \%)$ had a value above the NEFA cut-off value, and $32(7 \%)$ cows were positive in both tests. Only 5 cows had decreased fertility according to all 3 reference standards.

The results of the logistic models are presented in Table 4, and estimated strata-specific Se and Sp values are shown in Table 5. Generally, the estimated Sp of the different tests was higher when the test was used in cows of parity 1 or in cows in their second parity. For example, the Sp of the NEFA test when used to predict risk of ANEST was 87\% (95\% CI: 0.77-0.98) in a cow of parity 1 compared with $68 \%$ (95\% CI: $0.50-0.86$ ) in a cow of parity $\geq 3$. Correspondingly, the Se of the tests was highest in older cows; for example, the Se of the NEFA test when used to predict ANEST was $60 \%(95 \% \mathrm{CI}=0.37-0.84)$ in a cow of parity $\geq 3$ compared with $32 \%$ (95\% CI: 0.10-0.53) when used in a first calver. Breed was significant only for BHBA in the DFAI model, with an overall $P$-value of 0.009 . The overall fit of the models was considered satisfactory. Some covariate patterns with a large influence on the

Table 3. Cut-off values of plasma concentrations of NEFA, BHBA, and IGF-1 with the highest combined sensitivity (Se) and specificity (Sp) and the corresponding $95 \%$ CI when used to predict decreased fertility in dairy cows

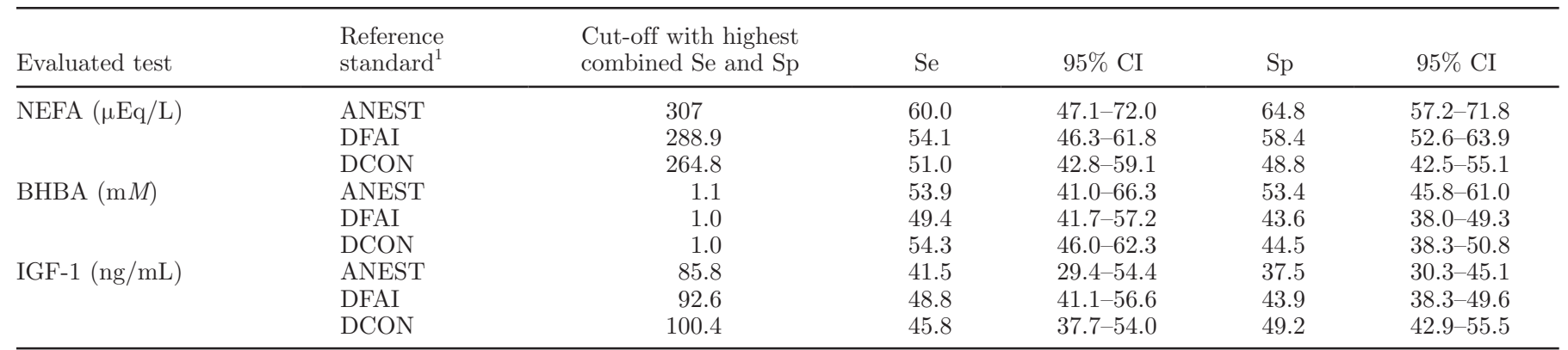

${ }^{1}$ ANEST $=$ anestrus; that is, whether a cow had a first luteal activity at 36 DIM or not $(\mathrm{n}=241)$; DFAI = delayed first AI; that is, whether the cow had a first AI at 96 DIM or not $(\mathrm{n}=480)$; CON = conception; that is, whether the cow had conceived or not at $145 \mathrm{DIM}(\mathrm{n}=407)$. 


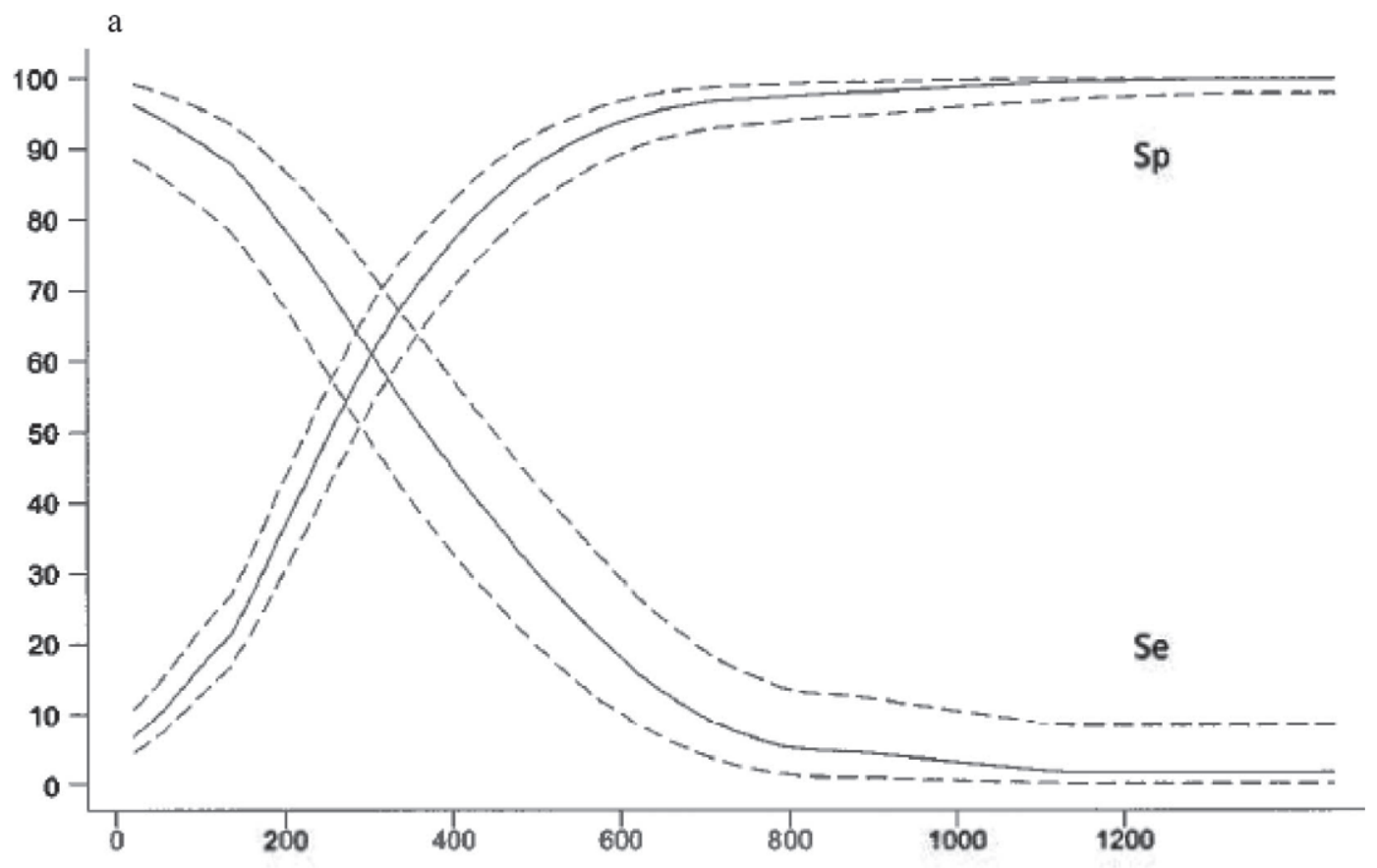

b

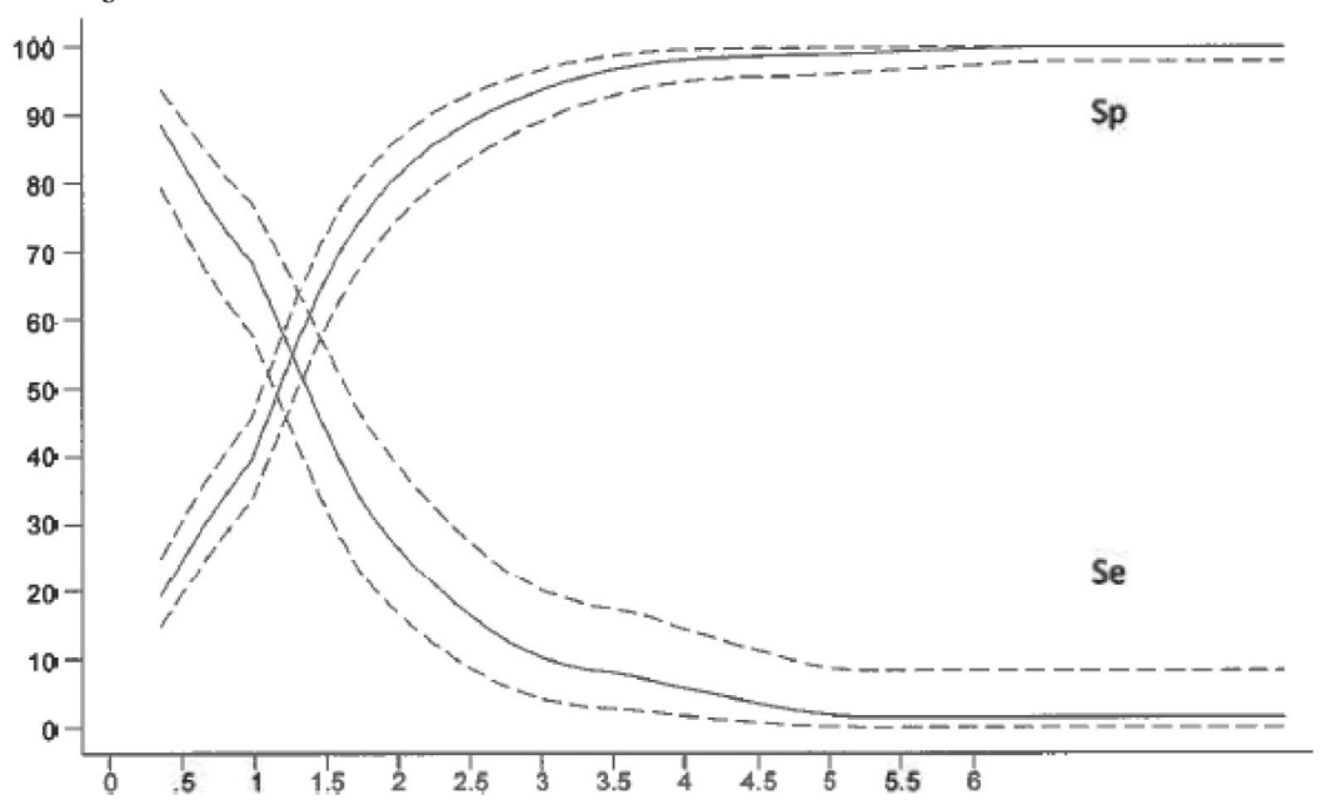

Figure 1. Diagnostic sensitivity (Se) and specificity (Sp) with their 95\% confidence intervals at different cut-off values when plasma concentrations of (a) NEFA and (b) BHBA were used as a test for anestrus in dairy cows ( $\mathrm{n}=241$; Sweden 2007-2009).

models were identified. Because no biological reason for dropping observations was identified, these were left in the models.

The PV+ and PV - at the cut-offs applied in the logistic models (i.e., aiming for a general Sp of at least $80 \%$ ), calculated for populations with different prevalence of decreased fertility, are shown in Table 6. In the herds included in this study, the true prevalence of
ANEST was 27\% (Table 1), which corresponded to a $\mathrm{PV}+$ between 0.36 and 0.45 , and a PV - between 0.76 and 0.79 for the NEFA and BHBA tests, respectively. The true prevalence of DFAI was $35 \%$, corresponding to a PV+ of 0.38 for the NEFA test and 0.29 for the BHBA test. The PV - when these tests were used to predict DFAI in the study population was approximately 0.65 for both tests. 


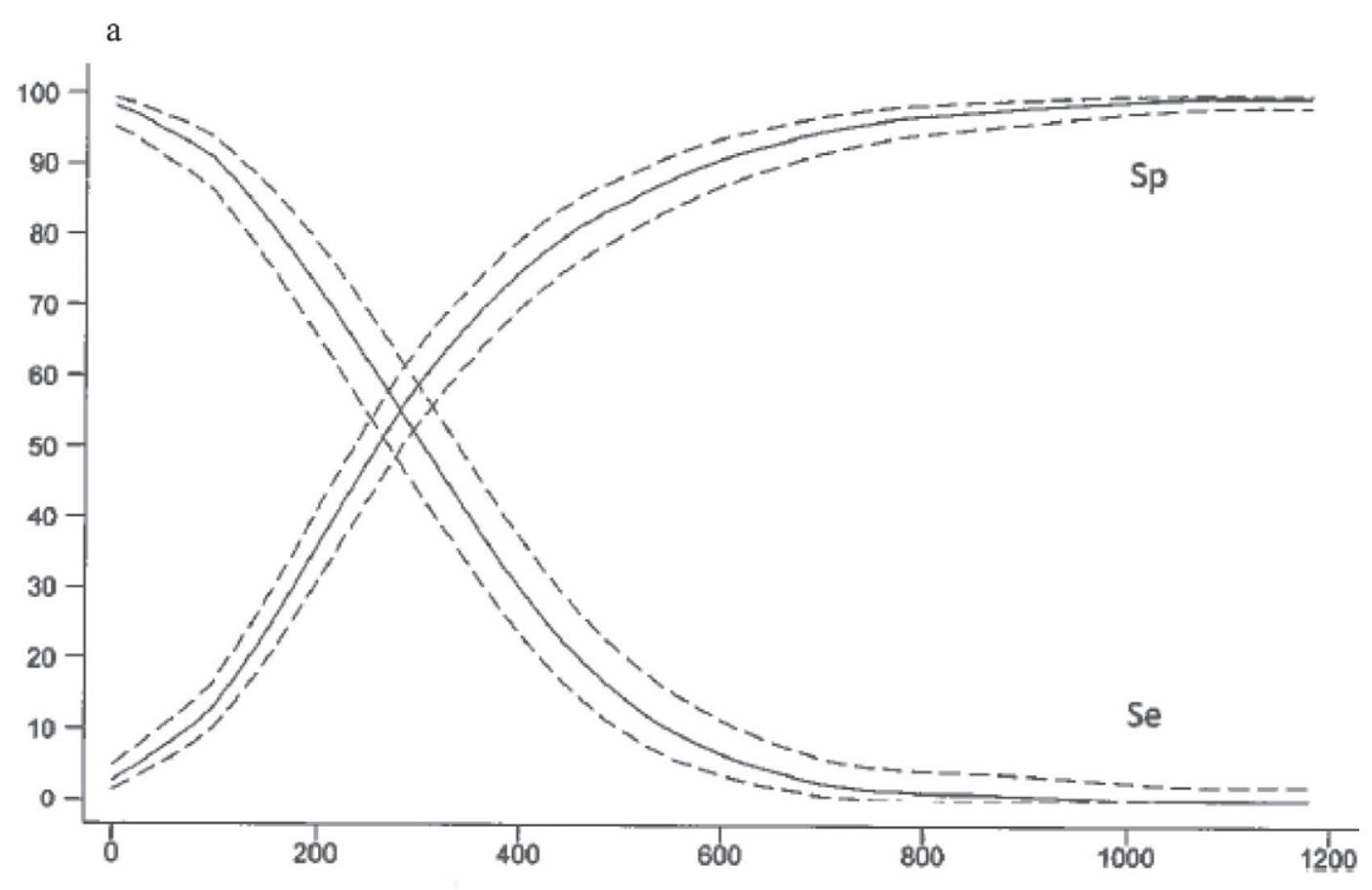

b

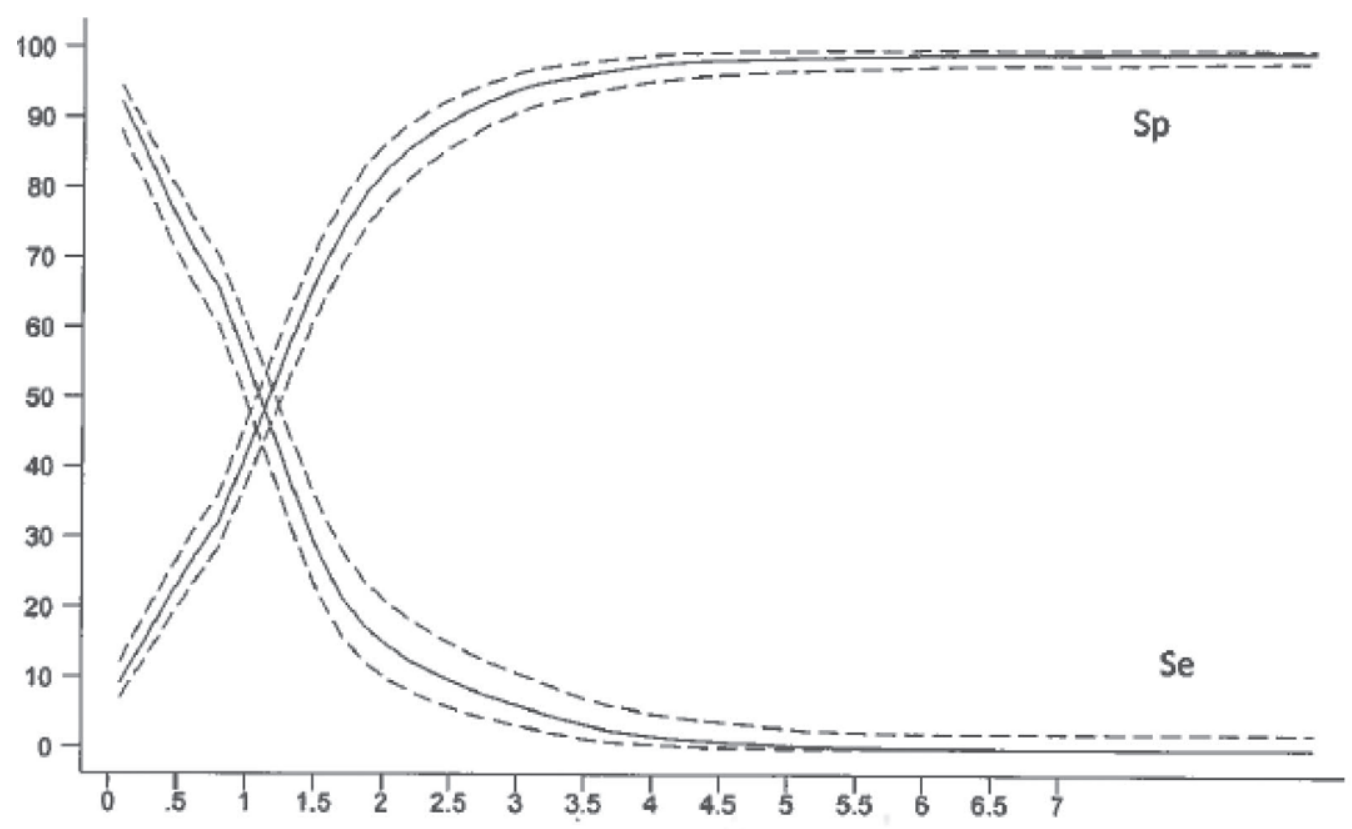

Figure 2. Diagnostic sensitivity (Se) and specificity (Sp) with their 95\% confidence intervals at different cut-off values when plasma concentrations of (a) NEFA and (b) BHBA were used as a test for delayed first AI in dairy cows ( $\mathrm{n}=480$; Sweden 2007-2009).

\section{DISCUSSION}

This study evaluated the accuracy of 3 indicators of NEB measured in single samples of plasma collected from 4 to 21 DIM when used to predict the risk of decreased fertility in dairy cows. Overall, the best combined Se and Sp for the evaluated tests was low. However, depending on the purpose of testing, these tests could still be useful. Our results provide a basis for decisions about which cut-off value to use in these tests based on the expected accuracy of the test, the prevalence of the event of interest, and, ultimately, the 
Table 4. Results from 4 models used to estimate the probability of having a plasma concentration of NEFA below or above $400 \mu \mathrm{Eq} / \mathrm{L}$ or BHBA below or above $1.8 \mathrm{~m} \mathrm{M}$ when predicted by parity and anestrus (ANEST; $0=$ no, $1=$ yes) in 241 dairy cows across 7 herds, or parity, breed, and delayed first AI (DFAI; $0=$ no, $1=$ yes) in 480 cows across 12 herds

\begin{tabular}{|c|c|c|c|c|c|c|}
\hline Model & $\begin{array}{l}\text { Explanatory } \\
\text { variable/level }\end{array}$ & $b^{1}$ & $\mathrm{SE}(b)^{2}$ & $P$-value & $\begin{array}{l}\text { Odds } \\
\text { ratio }\end{array}$ & $95 \%$ CI \\
\hline \multirow[t]{7}{*}{ NEFA } & Intercept & -1.93 & 0.49 & $<0.0001$ & & \\
\hline & $\begin{array}{l}\text { ANES I } \\
0\end{array}$ & $ـ_{3}^{3}$ & - & - & - & - \\
\hline & 1 & 1.17 & 0.36 & 0.001 & 3.22 & $1.60,6.48$ \\
\hline & Parity & & & & & \\
\hline & 1 & - & - & - & - & - \\
\hline & 2 & -0.17 & 0.46 & 0.71 & 0.84 & $0.34,2.06$ \\
\hline & $\geq 3$ & 1.17 & 0.40 & 0.004 & 3.23 & $1.46,7.13$ \\
\hline \multirow[t]{8}{*}{ BHBA } & Intercept & -2.78 & 0.55 & $<0.0001$ & & \\
\hline & ANEST & & & & & \\
\hline & 0 & - & - & - & - & - \\
\hline & 1 & 0.68 & 0.37 & 0.07 & 1.97 & $0.95,4.08$ \\
\hline & Parity & & & & & \\
\hline & 1 & - & - & - & - & - \\
\hline & 2 & 1.19 & 0.37 & 0.07 & 3.29 & $1.25,8.66$ \\
\hline & $\geq 3$ & 1.78 & 0.46 & $<0.0001$ & 5.92 & $3.39,14.65$ \\
\hline \multirow[t]{8}{*}{ NEFA } & Intercept & -1.46 & 0.32 & $<0.0001$ & & \\
\hline & DFAI & & & & & \\
\hline & 0 & - & - & - & - & - \\
\hline & 1 & -0.08 & 0.24 & 0.74 & 0.92 & $0.57,1.49$ \\
\hline & Parity & & & & & \\
\hline & 1 & - & - & - & - & - \\
\hline & 2 & -0.33 & 0.32 & 0.30 & 0.72 & $0.39,1.34$ \\
\hline & $\geq 3$ & 0.93 & 0.32 & $<0.0001$ & 2.54 & $1.51,4.27$ \\
\hline \multirow[t]{12}{*}{ BHBA } & Intercept & -2.07 & 0.36 & $<0.0001$ & & \\
\hline & DFAI & & & & & \\
\hline & 0 & - & - & - & - & - \\
\hline & 1 & -0.33 & 0.28 & 0.23 & 0.72 & $0.42,1.24$ \\
\hline & Parity & & & & & \\
\hline & 1 & - & - & - & - & - \\
\hline & 2 & 0.79 & 0.36 & 0.03 & 2.21 & $1.09,4.50$ \\
\hline & $\geq 3$ & 1.50 & 0.33 & $<0.0001$ & 4.50 & $2.34,8.64$ \\
\hline & Breed $^{4}$ & & & & & \\
\hline & SR & - & - & - & - & - \\
\hline & $\mathrm{SH}$ & -1.08 & 0.38 & 0.005 & 0.34 & $0.16,0.72$ \\
\hline & Other & -0.42 & 0.53 & 0.42 & 0.65 & $0.23,1.83$ \\
\hline
\end{tabular}

${ }^{1}$ Coefficient from model.

${ }^{2}$ Standard error of the $\beta$-value.

${ }^{3}$ Not applicable (reference standard).

${ }^{4} \mathrm{SR}=$ Swedish Red; $\mathrm{SH}=$ Swedish Holstein; Other $=$ other breed or crossbreed.

costs of false positive versus false negative results. Here, the tests were used to identify individual cows at risk of decreased fertility, so that preventive measures could be taken. Applying a cut-off value with a high Se would result in a large number of cows at risk to be treated, and many of these would also be false positives. In the further evaluation of the tests, a cut-off value with a high Sp was therefore chosen, which in practice would give a more reasonable number of cows at risk to be treated.

When strata-specific Se and Sp were calculated for explanatory variables that were significant in the logis- tic models, we found that Se was higher when the tests were used in animals of higher parity. In the NEFA test for ANEST, Se was nearly twice as high when the test was used for cows of third parity or older, compared with when it was used in first calvers. At the same time, Sp was higher in younger cows. Compared with older cows, first calvers had less variation in plasma concentrations of NEFA and BHBA. One explanation for this could be that cows of different parity may have different capacity to adapt to metabolic stress. Breed was significantly associated only with BHBA concentration and only when testing for DFAI. When plasma 
Table 5. Estimation of level-specific diagnostic sensitivity (Se) and specificity (Sp) for 2 tests based on cut-off values of plasma concentrations of NEFA or BHBA with a general Sp of $80 \%$, when used to predict cows in anestrus (ANEST) in 241 dairy cows across 7 herds or delayed first AI (DFAI) in 480 cows across 12 herds

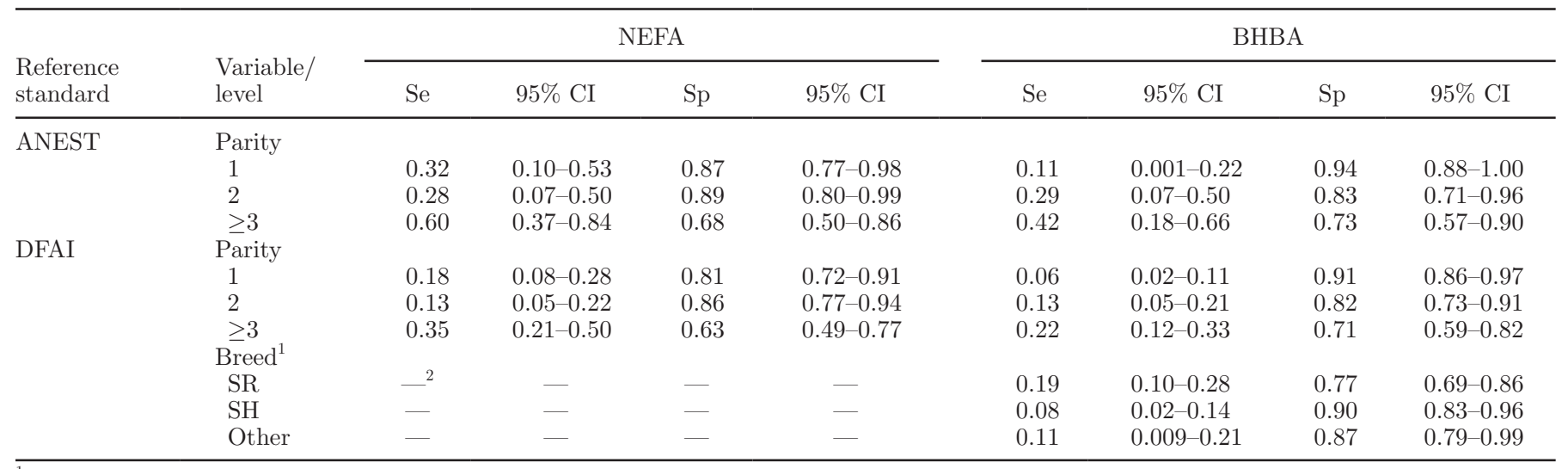

${ }^{1} \mathrm{SR}=$ Swedish Red; $\mathrm{SH}=$ Swedish Holstein; Other $=$ other breed or crossbreed.

${ }^{2}$ Not applicable.

concentrations of BHBA and NEFA are measured and interpreted in the field situation, it may be advisable to ignore breed, but to consider cow parity.

The usefulness of a diagnostic test varies depending on the prevalence of the event of interest (in this case, decreased fertility) in the group of animals to which the test is applied. In this study population, the PV+ was $<0.50$ for all tests and reference standards. This means that, given a positive test and the observed prevalence in the study population, the probability that the animal had decreased fertility was low. When the tests were applied to a hypothetical population with a higher prevalence of decreased fertility (e.g., when investigating a problem herd), the PV + of the tests increased but was still $<0.70$. Altogether, given a positive test and a high prevalence in the population, the probability that the animal actually had decreased fertility was $<68 \%$. On the other hand, given a negative test and a low prevalence, the probability that the cow had normal fertility was $>89 \%$. In other words, from a practical point of view, the usefulness of these test systems is limited.

The reference standards used to identify whether a cow had decreased fertility were defined as a cow experiencing FLA, FAI, or CON later than $75 \%$ of other cows in this data set. The 75th percentile of FAI and CON in all herds registered within SOMRS with 45 to 105 calving cows per year corresponded to 102 and 143 d (Swedish Dairy Association, 2009-2012), compared with 96 and 145 in this study. Anestrus is not routinely recorded within SOMRS, but Petersson et al. (2006) reported that $16 \%$ of cows had not started the cycle at 56 DIM. In the present study, cows were not followed as far as 56 DIM, but $27 \%$ were not cycling at 36 DIM. For decades, the Scandinavian countries have incorporated fertility traits into breeding goals (Philipsson and Lindhé, 2003) and, although decreased fertility is considered a problem, the prevalence is relatively low. In other populations of dairy cows with a higher prevalence of decreased fertility, the positive predictive

Table 6. Positive predicted values $(\mathrm{PV}+)$ and negative predicted values $(\mathrm{PV}-)$ when tests based on plasma concentrations of NEFA or BHBA were used in populations with different prevalence of anestrus (ANEST) and delayed first AI (DFAI)

\begin{tabular}{lccccccc}
\hline & \multicolumn{3}{c}{ ANEST prevalence (\%) } & & \multicolumn{3}{c}{ DFAI prevalence (\%) } \\
\cline { 2 - 3 } \cline { 7 - 8 } Test & 15 & $27^{1}$ & 50 & & 15 & $35^{1}$ & 50 \\
\hline NEFA & 0.27 & 0.45 & 0.68 & & 0.17 & 0.38 & 0.53 \\
PV+ & 0.89 & 0.79 & 0.59 & & 0.86 & 0.66 & 0.51 \\
PV- & 0.21 & 0.36 & 0.61 & & 0.11 & 0.29 & 0.43 \\
BHBA & 0.87 & 0.76 & 0.54 & & 0.84 & 0.64 & 0.48 \\
PV+ & & & & &
\end{tabular}

${ }^{1}$ Prevalence corresponding to the true prevalence in the study population. 
values of these tests will be higher and therefore the tests will be more accurate in identifying cows at risk of decreased fertility.

In this study, the NEFA cut-off value for further evaluation $(400 \mu \mathrm{Eq} / \mathrm{L})$ was chosen by favoring high Sp. Ospina et al. (2010a) used a higher NEFA cut-off value of $720 \mu \mathrm{Eq} / \mathrm{L}$ (serum) when evaluating the effects of increased fat mobilization on fertility. However, that threshold was set with the purpose of predicting displaced abomasum (estimated $\mathrm{Se}=0.75$ and $\mathrm{Sp}=$ 0.61 ), and no information is provided on $\mathrm{Se}$ and $\mathrm{Sp}$ at this cut-off value when the test is used to predict decreased fertility (Ospina et al., 2010b). Chapinal et al. (2011) found that an NEFA cut-off value of 1,000 $\mu \mathrm{Eq} / \mathrm{L}$ serum had $\mathrm{Se}=0.51$ and $\mathrm{Sp}=0.80$ when used to predict displaced abomasum. It is reasonable for a cut-off value used to predict clinical disease to be higher than that used to predict decreased fertility. When the NEFA cut-off value of $1,000 \mu \mathrm{Eq} / \mathrm{L}$ was applied in our study, the PV+ for ANEST was slightly better than that for the $400 \mu \mathrm{Eq} / \mathrm{L}$ cut-off value (data not shown).

The plasma BHBA cut-off value chosen for further evaluation in this study was $1.8 \mathrm{~m} M$. Serum BHBA concentrations of 1.2 to $1.4 \mathrm{mM}$ during the first or second week of lactation are indicative of subclinical ketosis (LeBlanc, 2010). In addition, Walsh et al. (2007) found that cows with serum concentrations $\geq 1.0 \mathrm{~m} M$ during the first week and $\geq 1.4 \mathrm{~m} M$ during the second week after calving were $50 \%$ less likely to be pregnant after first insemination. However, the results can be expected to depend on the prevalence of decreased fertility in the study population, and the diagnostic Se and Sp of the test were not estimated.

The Se and Sp of two or more tests can be increased by applying parallel testing (i.e., an animal is considered to be test-positive when it tests positive in one or both tests), which increases Se, or serial testing (i.e., only animals that test positive in both tests are considered test-positive), which increases Sp. The usefulness of the tests investigated in this study would probably be increased by interpreting the tests in combination. Serial interpretation of milk acetone and milk lactose measured during the first 4 wk after calving predicted luteal function with an Se of $84 \%$ and an Sp of $86 \%$ (Reksen et al., 2002). Several cow-side tests are available commercially for measuring BHBA in plasma, but NEFA and IGF-1 analyses must still be performed in the laboratory. As costs for analyses of plasma concentrations of NEFA, BHBA, and IGF-1 would be high when interpreting the test in combination, this approach was not further evaluated and reported in this study.

Results from the logistic regressions showed that cows in ANEST were significantly more likely to have NEFA concentrations in plasma of $>400 \mu \mathrm{Eq} / \mathrm{L}$. How- ever, no significant elevation in BHBA plasma concentration was detected in these cows. Cows with or without DFAI did not have significantly different probabilities of plasma concentrations above the modeled cut-off, for either NEFA or BHBA. Furthermore, no significant associations were found between test results and DCON (data not shown). The lack of significant associations between the metabolic indicators and the reference standards and DFAI and DCON and the poor performance of the test in predicting DCON were not surprising. The accuracy of the tests evaluated in this study relies predominantly on the relationship between NEB and decreased fertility. It is well known that the fertility parameters day of FAI and day of CON are also influenced by stock management; for example, the ability of the farmer to detect estrus and specific decisions made by the farmer. In contrast, tests for ANEST had higher Se and Sp, which might indicate that NEB has a large impact on resumption of ovarian cyclicity (Butler, 2003) and that the start of cyclicity in the cow is less dependent on farmers' decisions.

This study was based on analysis of single blood samples collected during the first $3 \mathrm{wk}$ postpartum. Plasma concentrations of metabolic indicators are not constant and change with increasing DIM. According to Jorritsma et al. (2003), the nadir in NEB occurs between 2 and $12 \mathrm{~d}$ postpartum. Here, some of the variation in the data was minimized because the period of most severe NEB was included in the sampling period. If samples had been taken at the nadir of NEB for each individual cow, the test results would likely have been more accurate. In addition, repeated and more frequent sampling could have improved the performance of the test systems. This has been illustrated in a study by Nielsen et al. (2005), where BHBA was measured frequently in milk and used in a biological model to predict clinical ketosis. However, in the present study, sampling within 3 wk was considered realistic, especially for smaller herds where veterinary visits are prone to occur at longer intervals. The mean herd size in Swedish dairy production is 63 milking cows on a yearly basis (Swedish Dairy Association, 2009-2012), and the material in this study reflects the field situation.

\section{CONCLUSIONS}

The results from this study confirmed that overall test performance was low for a single sample of plasma when NEFA, BHBA, or IGF-1 were measured in early lactation to predict the risk of decreased fertility in dairy cows. Test accuracy was influenced by individual cow parity and breed. Furthermore, the prevalence of the event of interest (in this case, decreased fertility) 
influenced test usefulness and should be considered when interpreting test results.

\section{ACKNOWLEDGMENTS}

This study was financially supported by The Swedish Farmers' Foundation for Agricultural Research (Stockholm, Sweden), Skaraborgs läns nötkreatursförsäkringsbolag (Skara, Sweden), and Alfa Laval AB's fund (Stockholm, Sweden). We gratefully acknowledge Torben Larsen and staff at the laboratory of Aarhus University (Denmark) for efficient handling of samples. We are also most grateful to the farmers who participated in this study for their enthusiastic help and interest.

\section{REFERENCES}

Butler, W. R. 2003. Energy balance relationships with follicular development, ovulation and fertility in postpartum dairy cows. Livest. Prod. Sci. 83:211-218.

Chapinal, N., M. Carson, T. F. Duffield, M. Capel, S. Godden, M. Overton, J. E. P. Santos, and S. J. LeBlanc. 2011. The association of serum metabolites with clinical disease during the transition period. J. Dairy Sci. 94:4897-4903.

Coughlin, S., B. Trock, M. Criqui, L. Pickle, D. Browner, and M. Tefft. 1992. The logistic modeling of sensitivity, specificity, and predictive value of a diagnostic test. J. Clin. Epidemiol. 45:1-7.

Dohoo, I., W. Martin, and H. Stryhn. 2009. Veterinary Epidemiologic Research. 2nd ed. VER Inc., Charlottetown, Prince Edward Island, Canada.

Friggens, N., M. Bjerring, C. Ridder, S. Höjsgaard, and T. Larsen. 2008. Improved detection of reproductive status in dairy cows using milk progesterone measurements. Reprod. Domest. Anim. 43:113-121.

Friggens, N. C. 2003. Body lipid reserves and the reproductive cycle: Towards a better understanding. Livest. Prod. Sci. 83:219-236.

Greiner, M., D. Sohr, and P. Göbel. 1995. A modified ROC analysis for the selection of cut-off values and the definition of intermediate results of serodiagnostic tests. J. Immunol. Methods 185:123-132.

Hosmer, D. V., and S. Lemeshow. 2000. Applied Logistic Regression. 2nd ed. John Wiley \& Sons Inc., New York, NY.

Inchaisri, C., R. Jorritsma, P. L. A. M. Vos, G. C. van der Weijden, and H. Hogeveen. 2010. Economic consequences of reproductive performance in dairy cattle. Theriogenology 74:835-846.

Ingvartsen, K. L. 2006. Feeding- and management-related diseases in the transition cow. Physiological adaptations around calving and strategies to reduce feeding-related diseases. Anim. Feed Sci. Technol. 126:175-213.

Ingvartsen, K. L., and J. B. Andersen. 2000. Integration of metabolism and intake regulation: A review focusing on periparturient animals. J. Dairy Sci. 83:1573-1597.

Jorritsma, R., T. Wensing, T. A. Kruip, P. L. Vos, and J. P. Noordhuizen. 2003. Metabolic changes in early lactation and impaired reproductive performance in dairy cows. Vet. Res. 34:11-26.

LeBlanc, S. 2010. Monitoring metabolic health of dairy cattle in the transition period. J. Reprod. Dev. 56(Suppl.):S29-S35.

Lomander, H., J. Frössling, K. L. Ingvartsen, H. Gustafsson, and C. Svensson. 2012a. Supplemental feeding with glycerol or propylene glycol of dairy cows in early lactation-Effects on metabolic status, body condition and milk yield. J. Dairy Sci. 95:2397-2408.

Lomander, H., H. Gustafsson, J. Frössling, K. L. Ingvartsen, T. Larsen, and C. Svensson. 2012b. Effect of supplemental feeding with glycerol or propylene glycol in early lactation on fertility in Swedish dairy cows. Reprod. Domest. Anim. http://dx.doi. org $/ 10.1111 / \mathrm{j} .1439-0531.2012 .02004 . x$

Løvendahl, P., and H. M. Purup. 2002. Technical note: Time-resolved fluoro-immunometric assay for intact insulin in livestock species. J. Anim. Sci. 80:191-195.

Nielsen, N. I., N. C. Friggens, M. G. G. Chagunda, and K. L. Ingvartsen. 2005. Predicting risk of ketosis in dairy cows using in-line measurements of $\beta$-hydroxybuturate: A biological model. J. Dairy Sci. 88:2441-2453

Ospina, P. A., D. V. Nydam, T. Stokol, and T. R. Overton. 2010a. Associations of elevated nonesterified fatty acids and $\beta$-hydroxybutyrate concentrations with early lactation reproductive performance and milk production in transition dairy cattle in the northeastern United States. J. Dairy Sci. 93:1596-1603.

Ospina, P. A., D. V. Nydam, T. Stokol, and T. R. Overton. 2010b. Evaluation of nonesterified fatty acids and $\beta$-hydroxybutyrate in transition dairy cattle in the northeastern United States: Critical thresholds for prediction of clinical diseases. J. Dairy Sci. 93:546-554.

Patton, J., D. A. Kenny, S. McNamara, J. F. Mee, F. P. O'Mara M. G. Diskin, and J. J. Murphy. 2007. Relationships among milk production, energy balance, plasma analytes, and reproduction in Holstein-Friesian cows. J. Dairy Sci. 90:649-658.

Petersson, K.-J., H. Gustafsson, E. Strandberg, and B. Berglund. 2006. Atypical progesterone profiles and fertility in Swedish dairy cows. J. Dairy Sci. 89:2529-2538.

Philipsson, J., and B. Lindhé. 2003. Experiences of including reproduction and health traits in Scandinavian dairy cattle breeding programmes. Livest. Prod. Sci. 83:99-112.

Reksen, O., Ø. Havrevoll, Y. T. Gröhn, T. Bolstad, A. Waldmann, and E. Ropstad. 2002. Relationships among body condition score, milk constituents, and postpartum luteal function in Norwegian dairy cows. J. Dairy Sci. 85:1406-1415.

Rodriguez-Martinez, H., J. Hultgren, R. Båge, A.-S. Bergqvist, C. Svensson, C. Bergsten, L. Lidfors, S. Gunnarsson, B. Algers, U. Emanuelsson, B. Berglund, G. Andersson, M. Håård, B. Lindhé, H. Stålhammar, and H. Gustafsson. 2008. Reproductive performance in high-yielding dairy cows: Can we sustain it under current practice? IVIS Reviews in Veterinary Medicine. Document No. R0108.1208. International Veterinary Information Service Ithaca, NY. Accessed Aug. 27, 2012. http://www.ivis.org/reviews/rev/ rodriguez/chapter.asp?LA=1.

Spörndly, R. 2003. Fodertabeller för idisslare 2003. SLU Institutionen för husdjurens utfodring och vård. Vol. 257. SLU, Uppsala, Sweden.

Swedish Dairy Association. 2009-2012. Cattle statistics. Swedish Dairy Association, Stockholm, Sweden. (In Swedish)

Velazquez, M. A., L. J. Spicer, and D. C. Wathes. 2008. The role of endocrine insulin-like growth factor-I (IGF-I) in female bovine reproduction. Domest. Anim. Endocrinol. 35:325-342.

Walsh, R. B., J. S. Walton, D. F. Kelton, S. J. LeBlanc, K. E. Leslie, and T. F. Duffield. 2007. The effect of subclinical ketosis in early lactation on reproductive performance of postpartum dairy cows. J. Dairy Sci. 90:2788-2796.

Wathes, D. C., N. Bourne, Z. Cheng, G. E. Mann, V. J. Taylor, and M. P. Coffey. 2007. Multiple correlation analyses of metabolic and endocrine profiles with fertility in primiparous and multiparous cows. J. Dairy Sci. 90:1310-1325. 